\title{
Laboratory studies on bedload transport under unsteady flow conditions
}

\author{
Magdalena M. Mrokowska ${ }^{1 *}$, Paweł M. Rowiński ${ }^{1}$, Leszek Książek ${ }^{2}$, Andrzej Strużyński $^{2}$, Maciej \\ Wyrębek $^{2}$, Artur Radecki-Pawlik ${ }^{2,3}$ \\ ${ }^{1}$ Institute of Geophysics, Polish Academy of Sciences, ul. Ks. Janusza 64, 01-452 Warsaw, Poland. \\ ${ }^{2}$ University of Agriculture in Krakow, Faculty of Environmental Engineering and Land Surveying, Department of Hydraulic Engineering \\ and Geotechnics, Al. Mickiewicza 24/28, 30-059 Kraków, Poland. \\ ${ }^{3}$ Institute of Structural Mechanics, Cracow University of Technology, ul. Warszawska 24, 31-155 Kraków, Poland. \\ * Corresponding author. Tel.: +48 226915 849. Fax: +48 228776 722. E-mail: m.mrokowska@igf.edu.pl
}

\begin{abstract}
Two sets of triangular hydrographs were generated in a 12-m-long laboratory flume for two sets of initial bed conditions: intact and water-worked gravel bed. Flowrate ranging from $0.0013 \mathrm{~m}^{3} \mathrm{~s}^{-1}$ to $0.0456 \mathrm{~m}^{3} \mathrm{~s}^{-1}$, water level ranging from $0.02 \mathrm{~m}$ to $0.11 \mathrm{~m}$, and cumulative mass of transported sediment ranging from $4.5 \mathrm{~kg}$ to $14.2 \mathrm{~kg}$ were measured. Then, bedload transport rate, water surface slope, bed shear stress, and stream power were evaluated. The results indicated the impact of initial bed conditions and flow unsteadiness on bedload transport rate and total sediment yield. Difference in ratio between the amount of supplied sediment and total sediment yield for tests with different initial conditions was observed. Bedload rate, bed shear stress, and stream power demonstrated clock-wise hysteretic relation with flowrate. The study revealed practical aspects of experimental design, performance, and data analysis. Water surface slope evaluation based on spatial water depth data was discussed. It was shown that for certain conditions stream power was more adequate for the analysis of sediment transport dynamics than the bed shear stress. The relations between bedload transport dynamics, and flow and sediment parameters obtained by dimensional and multiple regression analysis were presented.
\end{abstract}

Keywords: Bedload; Bed shear stress; Dimensional analysis; Hysteresis; Stream power; Unsteady flow.

\section{INTRODUCTION}

Unsteadiness of water flow in rivers may be caused by both natural and accidental events, namely by heavy rainfall in a catchment, snow melt, breaking of log or ice-jams, operation of control gates, tides in estuaries or tidal rivers causing backwater effects. Flow unsteadiness intensifies transport processes, causes morphological changes in rivers, and affects water quality (De Sutter et al., 2001; Galia and Hradecky, 2011; Gharbi et al., 2016; Julien et al., 2002; Mao, 2012; Michalik and Książek, 2009). However, our knowledge on how matter, particularly sediment, is transported under unsteady flow conditions is still insufficient. This situation triggered a good deal of experimental, theoretical and computational efforts exploring how it works (Bombar, 2016; De Sutter et al., 2001; Julien et al., 2002; Lee et al., 2004; Mao, 2012; Mrokowska et al., 2016; Phillips and Sutherland, 1990; Wang et al., 2015). Nevertheless, the problem of bedload transport is still open for systematic research.

The processes involved in bedload transport are complex and case specific, which makes bedload transport difficult to express in general mathematical relations (Cao et al., 2016). Although there are multiple numerical models allowing for the predictions of bedload transport under unsteady flow conditions, such models seem not reliable and useful for the prediction purposes and not validated against sufficient amount of reliable datasets.

Laboratory experiments and field observations have revealed a variety of bedload transport patterns during the passage of flood waves. These patterns are due to the mutual effect of the water flow conditions and bed composition. Bedload transport rate - flowrate relationship under unsteady flow usually takes the form of clockwise or anti-clockwise hysteresis (Humphries et al., 2012; Mao, 2012; Moog and Whiting, 1998). It is hardly surprising that unsteady flows are intertwined with hysteretic behaviour as observed with respect to many variables (see e.g. O'Kane, 2005; Rajwa-Kuligiewicz et al., 2015; Rowiński et al., 2000).

Mao (2012) reported a clockwise hysteresis in experimental tests and attributed this type of relation to changes in organization of bed surface grains, which caused smaller bedload transport along the falling limb. Kuhnle (1992) observed a clockwise hysteresis in natural streams and attributed this pattern of transport to the formation and destruction of roughness elements. Bombar et al. (2011) reported an anti-clockwise hysteresis in experiments with a static armour layer, where the maximum bedload transport was possible only after the peak flowrate, when the armour layer was destroyed by a high flow. When sediment is heterogeneous, sediment transport is affected by grain arrangement (Ockelford and Haynes, 2013): microforms (clusters) are formed (Mao, 2012), static or mobile armour layer appears (Guney et al., 2013), and partial transport may take place (Sun et al., 2015). To make things more complicated, bedload transport is additionally controlled by the availability of upstream sediment in supply-limited rivers (Mao et al., 2011).

Contrary to the unsteady flow, a large number of bedload transport relations have been derived for steady flow conditions (Dey, 2014; Haddadchi et al., 2013; Talukdar et al., 2012; Yalin, 1972). Under unsteady flow, bedload transport is claimed to be more intensive than under corresponding steady flow. Similarly, total sediment yield is larger than evaluated for corresponding steady flow conditions (Tabarestani and Zarrati, 2015). Therefore, more and more researchers strive to develop methods dedicated to the unsteady flow, and cease to approximate it by step-wise steady flow conditions (Tabarestani and Zarrati, 2015).

A number of laboratory cases were studied experimentally with respect to bedload transport under unsteady flow. They varied in terms of various factors, such as the shape of unsteady 
flow hydrograph, e.g., triangular (Lee et al., 2004), trapezoidal (Bombar et al., 2011), step-wise (Mao, 2012), naturally shaped (Humphries et al., 2012); bed composition - uni-modal or bimodal (Wang et al., 2015); supply of sediment from upstream (Mao, 2012); initial bed conditions - armoured bed (Bombar et al., 2011) and not armoured bed (Humphries et al., 2012), or duration of flow from a few minutes (Guney et al., 2013) to a few hours (Mao, 2012). Some studies took into account or commented on scaling from natural to laboratory conditions, e.g., (Cooper and Tait, 2009; Wang et al., 2015).

In this paper, experimental data on gravel bedload transport are analysed. Preliminary results limited to just a few experimental sets and a detailed description of the experiments were published by Mrokowska et al. (2016). Herein, new experimental tests with water-worked initial bed conditions are reported. The aim of this paper is to assess the extent to which initial bed conditions and unsteadiness of flow affect bedload transport intensity and total sediment yield. The paper focuses on the impact of flowrate, bed shear stress and stream power on bedload transport dynamics and on the relations between parameters governing transport processes.

\section{MATERIAL AND METHODS Experimental set-up}

The experiment on bedload transport under unsteady flow was performed in a 12 -m-long, 0.485 -m-wide and 0.60-m-deep flow-recirculating tilting flume with glass side walls in the laboratory of Faculty of Environmental Engineering and Land Surveying, Agricultural University in Kraków, Poland (Fig. 1). Detailed description of the experimental settings were given by Mrokowska et al. (2016), so we just provide a brief summary with indication of aspects not mentioned in the previous paper.

A total of 10 experimental tests were carried out under unsteady flow conditions. The tests were classified according to the characteristics of flow and initial bed conditions. For each test, the channel bottom was covered with 12-cm-thick gravel layer that was well-mixed and screeded. Initial bed was composed of uniformly graded fine gravel with mean grain size $d_{m}=4.93 \mathrm{~mm}$ and maximum grain size $d_{\max }=18 \mathrm{~mm}$. These initial bed conditions were denoted by '-'. In some experimental tests, the bed was additionally water-worked by subthreshold steady flow for about one hour and such initial conditions were denoted by ' + '. During all tests, sediment was supplied manually from upstream to prevent excess scouring and deposition. Bed slope was constant for all tests $I=0.0083$.

Two sets of unsteady flow, namely Hyd1 and Hyd2, in the form of triangular hydrographs were generated by manual stepwise changing of valve opening. Both hydrographs were generated for two sets of initial bed conditions '-' and '+', a few times for each condition. Experimental tests were denoted

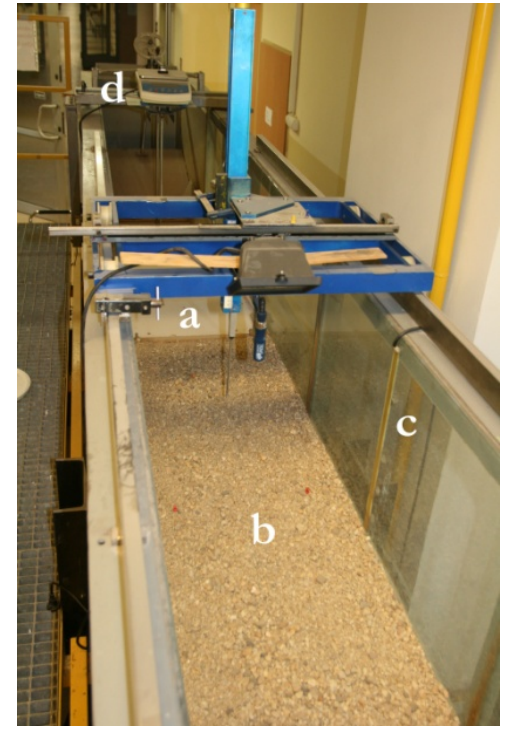

Fig. 1. Experimental channel - the closing section: a) non movable bed, b) movable bed, c) resistive water level sensor, d) bedload trap element - weighing scale.

Table 1. Classification of the experimental tests.

\begin{tabular}{|c|c|c|c|c|c|c|}
\hline & \multicolumn{3}{|c|}{ Hyd1 } & \multicolumn{3}{c|}{ Hyd2 } \\
\hline Bed- & Hyd1-1 & Hyd1-2 & Hyd1-3 & Hyd2-1 & Hyd2-2 & \\
\hline Bed+ & Hyd1+1 & Hyd1+2 & & Hyd2+1 & Hyd2+2 & Hyd2+3 \\
\hline
\end{tabular}

by Hyd(no)_(-or+)_(test no), where the first term stands for the type of hydrograph, the second for the initial bed conditions, and the third one for the number of experimental tests with conditions described by preceding terms. The tests are listed in Table 1.

The following variables were measured: flowrate in delivery inlet pipe by ultrasonic flow meter, water level in 5 profiles along the flume $x=2.6 \mathrm{~m}, x=3.6 \mathrm{~m}, x=4.6 \mathrm{~m}, x=5.6 \mathrm{~m}, x=$ $6.6 \mathrm{~m}$ with spatial step $\Delta x=1 \mathrm{~m}$ by resistive sensors, and cumulative mass of sediment measured in the outlet of the flume. Relevant hydrographs and cumulative sediment mass data are depicted in Fig. 2.

The characteristics of the unsteady flow experiments are listed in Table 2. The unsteady flow conditions are characterized by base flow $\left(Q_{b}\right)$, peak flow $\left(Q_{\max }\right)$, base water depth $\left(h_{b}\right)$, peak water depth $\left(h_{\max }\right)$, and duration of the rising limb $\left(t_{\mathrm{r}}\right)$. Also, Froude number for peak flow $\left(F r_{\max }\right)$ was evaluated. Subscript $_{\mathrm{b}}$ stands for base flow, $\max$ for the maximum value of a variable, ${ }_{r}$ for the rising limb of a wave, and ${ }_{f}$ for the falling limb of a wave. Figure 3 presents definitions of terms used to describe the flow characteristics. The two sets of unsteady flow differed in steepness of their limbs expressed as $\mathrm{d} Q / \mathrm{d} t$

Table 2. Characteristics of the experimental tests.

\begin{tabular}{|c|c|c|c|c|c|c|c|c|c|c|c|c|c|}
\hline Run & $\begin{array}{c}t_{\mathrm{r}} \\
(\mathrm{s})\end{array}$ & $\begin{array}{c}\alpha_{\mathrm{r}} \times 10^{-3} \\
(-)\end{array}$ & $\begin{array}{c}\alpha_{\mathrm{f}} \times 10^{-3} \\
(-)\end{array}$ & $\begin{array}{c}P_{\mathrm{gt}} \\
(-)\end{array}$ & $\begin{array}{c}Q_{\mathrm{b}} \\
\left(\mathrm{m}^{3} \mathrm{~s}^{-1}\right)\end{array}$ & $\begin{array}{c}Q_{\max } \\
\left(\mathrm{m}^{3} \mathrm{~s}^{-1}\right)\end{array}$ & $\begin{array}{c}h_{\mathrm{b}} \\
(\mathrm{m})\end{array}$ & $\begin{array}{c}h_{\max } \\
(\mathrm{m})\end{array}$ & $\begin{array}{c}U_{\mathrm{b}} \\
\left(\mathrm{m} \mathrm{s}^{-1}\right)\end{array}$ & $\begin{array}{c}U_{\max } \\
\left(\mathrm{m} \mathrm{s}^{-1}\right)\end{array}$ & $\begin{array}{c}\tau_{\mathrm{b}} \\
\left(\mathrm{N} \mathrm{m}^{2}\right)\end{array}$ & $\begin{array}{c}\tau_{\max } \\
\left(\mathrm{N} \mathrm{m}^{2}\right)\end{array}$ & $\begin{array}{c}F r_{\max } \\
(-)\end{array}$ \\
\hline Hyd1-1 & 406 & 0.10 & -0.11 & 0.0081 & 0.0013 & 0.0414 & 0.02 & 0.10 & 0.20 & 0.92 & 1.13 & 6.69 & 0.98 \\
\hline Hyd1-2 & 407 & 0.10 & -0.10 & 0.0081 & 0.0022 & 0.0435 & 0.02 & 0.10 & 0.25 & 0.87 & 1.40 & 8.12 & 0.94 \\
\hline Hyd1-3 & 404 & 0.09 & -0.09 & 0.0081 & 0.0020 & 0.0387 & 0.02 & 0.10 & 0.23 & 0.81 & 1.49 & 7.72 & 0.87 \\
\hline Hyd1+1 & 277 & 0.12 & -0.11 & 0.0082 & 0.0123 & 0.0456 & 0.05 & 0.11 & 0.52 & 0.89 & 3.67 & 7.10 & 0.92 \\
\hline Hyd1+2 & 267 & 0.12 & -0.11 & 0.0082 & 0.0114 & 0.0429 & 0.05 & 0.10 & 0.53 & 0.86 & 3.48 & 7.38 & 0.89 \\
\hline Hyd2-1 & 262 & 0.15 & -0.15 & 0.0081 & 0.0030 & 0.0405 & 0.02 & 0.10 & 0.33 & 0.90 & 1.47 & 7.05 & 0.99 \\
\hline Hyd2-2 & 257 & 0.16 & -0.16 & 0.0081 & 0.0035 & 0.0429 & 0.02 & 0.10 & 0.29 & 0.85 & 2.00 & 7.69 & 0.89 \\
\hline Hyd2+1 & 170 & 0.18 & -0.16 & 0.0081 & 0.0131 & 0.0419 & 0.05 & 0.10 & 0.54 & 0.867 & 3.80 & 7.40 & 0.87 \\
\hline Hyd2+2 & 168 & 0.17 & -0.16 & 0.0081 & 0.0122 & 0.0420 & 0.05 & 0.10 & 0.53 & 0.86 & 3.83 & 7.67 & 0.86 \\
\hline Hyd2+3 & 176 & 0.18 & -0.16 & 0.0081 & 0.0129 & 0.0432 & 0.05 & 0.10 & 0.57 & 0.88 & 3.51 & 7.21 & 0.88 \\
\hline
\end{tabular}



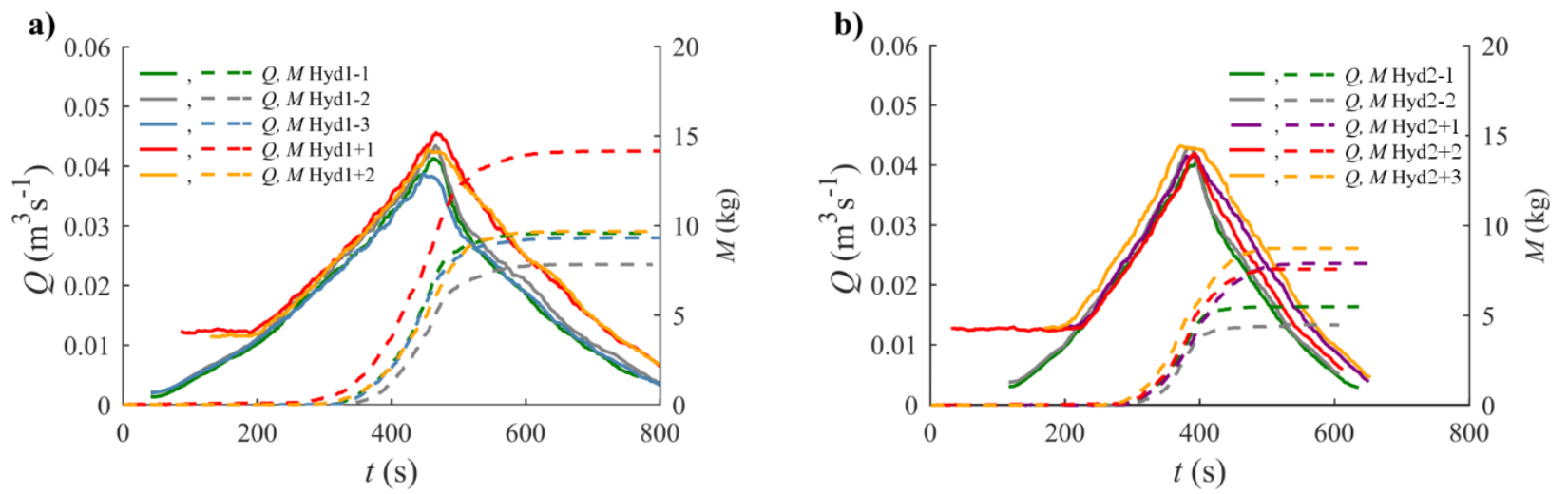

Fig. 2. Flowrate $(Q)$ and cumulative sediment mass $(M)$ measured during the experimental tests; a) Hyd1, b) Hyd2. Only a fraction of steady sub-threshold flow from one-hour flow is depicted for water-worked bed tests Hyd+.

a)

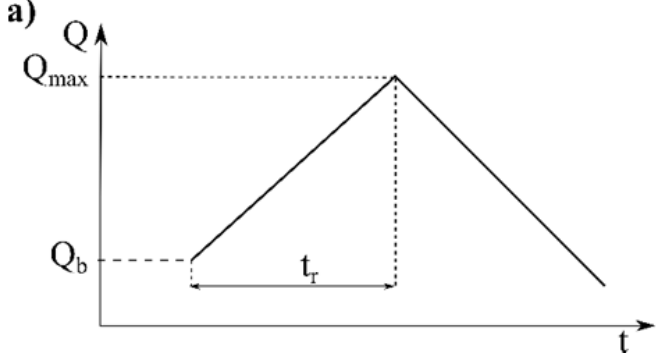

b)

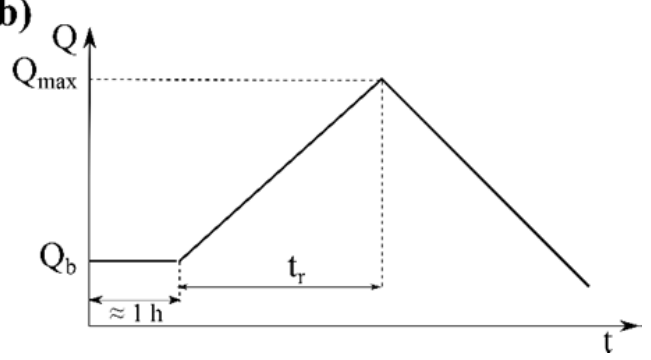

Fig. 3. Definition sketch of the terms used to characterize unsteady flow experiments; a) intact bed ('-'), b) water-worked bed ('+').

(Wang et al., 2015), denoted by $\alpha_{r}$ and $\alpha_{f}$ for the rising and the falling limb, respectively. Parameter $\alpha$ is referred to as the rate of unsteadiness in this study. Additionally, unsteadiness parameter introduced by (Bombar et al., 2011) was evaluated:

$P_{g t}=\frac{\left|g I-\frac{U_{\max }-U_{b}}{t_{r}}\right|}{g}$

where $g$ - gravitational acceleration $\left(\mathrm{m} \mathrm{s}^{-2}\right), I-$ bed slope $(-)$, $U-$ mean flow velocity $\left(\mathrm{m} \mathrm{s}^{-1}\right)$.

\section{Data processing and analysis}

Evaluation of bedload transport rate

Bedload transport may be expressed by cumulative mass, bedload transport rate, i.e., solid volume/weight/submerged weight of sediment transported per unit time, or by bedload transport intensity in non-dimensional form (Dey, 2014). In this study, weight of the sediment transported per unit time $(q)$ was evaluated from cumulative sediment mass data $(M)$ collected during the experimental tests.

Savitzky-Golay filter (Savitzky and Golay, 1964) was applied to smooth the raw cumulative transport data and to evaluate the bedload rate. Suitability of this method was demonstrated by Mrokowska et al. (2016) in selected experimental datasets.

This paper confirmed that the results of Savitzky-Golay filter were compatible with those obtained by approximating the data with a difference quotient and then by Fourier Transform filtering that is very popular in unsteady flow data smoothing (Bagherimiyab and Lemmin, 2013; Rowiński and Czernuszenko, 1998; Song and Graf, 1996). Nonetheless, in this case, Savitzky-Golay filter appeared to be superior to the other one thanks to its straightforward application; it also produced much fewer oscillations.

\section{Evaluation of water surface slope}

Water surface slope $\left(S_{w}\right)$ reflects the pattern of flow but it is also used as an approximation of energy slope when applicable, i.e., under equilibrium steady flow and unsteady diffusive flow. $S_{w}$ may be evaluated as a difference quotient, provided spatial measurements of water level in several locations along the channel are available (Mrokowska et al., 2015b).

It is more difficult to control and evaluate water surface slope than the flowrate in unsteady flow, which has been broadly discussed in the literature (Dottori et al., 2009; Mrokowska et al., 2015b; Perumal et al., 2004). Moreover, water surface slope results are very sensitive to the fluctuations of water level data. Minor spatial fluctuations of water level $(H)$ may cause water slope evaluated from water level data to vary in unexpected way. For this reason, the application of various difference quotients was compared in this study. Water surface slope was evaluated in the central measuring profile $x=4.6 \mathrm{~m}$ as a central difference quotient, Eq. (2), and a five point quotient, Eq. (3).

$$
\begin{aligned}
& S_{w} \approx \frac{H(x+\Delta x)-H(x-\Delta x)}{2 \Delta x}, \\
& S_{w} \approx \frac{-H(x+2 \Delta x)+8 H(x+\Delta x)-8 H(x-\Delta x)+H(x-2 \Delta x)}{12 \Delta x}
\end{aligned}
$$

The results were then filtered using Fourier Transform. Thanks to this low-pass filter, data fluctuations of undesired frequencies were removed. Satisfactory results were obtained for threshold frequency $0.03 \mathrm{~Hz}$. A time series of water surface slope was transformed into the frequency domain and only components lower than the threshold frequency were taken.

Then, filtered data were transformed back to time domain. More details on Fourier Transform application may be found in (Bendat and Piersol, 2010; Mrokowska et al., 2015b; Song and Graf, 1996). 


\section{Evaluation of bed shear stress and stream power}

Analysis of the relations between bed shear stress and bedload transport rate during flood wave propagation may provide important information on the relations between water flow and bedload transport. It is, in fact, a subject of ongoing debate and multiple interpretations (Guney et al., 2013; Mao et al., 2011; Mrokowska et al., 2016).

Under unsteady mobile bed conditions, measurement of bed shear stress is subject to high degree of uncertainty. A definition of bed shear stress under mobile bed conditions is not straightforward (Ferreira et al., 2012; Nikora et al., 2007), and for this reason the measurements of bed shear stress require cautious interpretation. Moreover, it should be noted that methods that may be applied under unsteady flow are scarce, mainly due to theoretical assumptions (Mrokowska et al., 2015a). Formulae derived from Saint-Venant model have become popular in unsteady flow experiments (Bombar, 2016; Song and Graf, 1996; Mrokowska et al., 2015b). However, the question about their applicability in evaluating bed shear stress under mobile bed conditions remains unanswered. Saint-Venant model was derived for fixed beds and its results applied to mobile bed conditions may be burdened with possible significant errors. The same applies to other methods of anticipation.

In this study, bed shear stress $\tau_{b}\left(\mathrm{~N} \mathrm{~m}^{-2}\right)$ was evaluated using the formula that may be derived from the Saint-Venant model for a diffusive wave:

$\tau_{b}=\rho g h S_{\mathrm{w}}$

where $\rho$ - density of water $\left(\mathrm{kg} \mathrm{m}^{-3}\right), h$ - water depth (m). Next, bed shear stress was corrected for side-wall effects using the procedure proposed by Guo (2015).

Another widely used concept for bedload transport is stream power $(\omega)$ characteristic for Bagnold approach. While bed shear stress refers to forces exerted on a channel bed, stream power refers to the rate of energy necessary to transport sediment. It is applied as an indicator of channel sensitivity to deposition and erosion (Bizzi and Lerner, 2015), and to predict bed form type (Dey, 2014). In this study, stream power was evaluated using the following formula:

$\omega=\tau_{b} U$

\section{Dimensional and multiple regression analysis}

Dimensional analysis provides methods for reducing the number of phenomena describing variables by classifying them into dimensionless groups (Dey, 2014; Ettema, 2000). This classical method was applied to find the relationships for bedload transport in other studies as well (Ahanger et al., 2008; Sinnakaudan et al., 2006).

Bedload transport is controlled by a number of variables: $M$ - cumulative mass, $U$ - mean flow velocity, $h$ - flow depth, $\rho$ - water mass density, $\rho_{s}-$ mass density of sediment particles, $\Delta g=\left(\rho_{s}-\rho\right) g / \rho-$ reduced gravity, $g-$ gravitational acceleration, $v$ - kinematic viscosity of water, $d$ - sediment particle diameter, $t$ - time elapsed from beginning of transport. The variables are of the following dimensions ( $\mathrm{M}$ - mass, $\mathrm{L}$ - length, T - time): $M[\mathrm{M}] ; d[\mathrm{~L}] ; v\left[\mathrm{~L}^{2} \mathrm{~T}^{-1}\right] ; \Delta g\left[\mathrm{LT}^{-2}\right] ; U$ $\left[\mathrm{LT}^{-1}\right] ; h[\mathrm{~L}] ; \rho\left[\mathrm{ML}^{-3}\right]$. The functional relationship between cumulative mass as a dependent variable and other variables is as follows:

$f(M, d, v, \Delta g, t, \rho, h, U)=0$
Buckingham $\pi$-theorem was applied to identify dimensionless parameters. $M, h$, and $\Delta g$ were taken as the repeating variables. Having three dimensions, 8 variables reduced to 5 nondimensional parameters:

$$
\begin{aligned}
& \pi_{1}=\Delta g^{-0.5} h^{-0.5} U \\
& \pi_{2}=\Delta g^{-0.5} h^{-1.5} v \\
& \pi_{3}=h^{-1} d \\
& \pi_{4}=\Delta g^{0.5} t h^{-0.5} \\
& \pi_{5}=M^{-1} h^{3} \rho
\end{aligned}
$$

The set of dimensionless parameters formed the following relation:

$$
f\left(h^{-1} d, \Delta g^{-0.5} h^{-1.5} v, \Delta g^{0.5} t h^{-0.5}, \Delta g^{-0.5} h^{-0.5} U, M^{-1} h^{3} \rho\right)=0 .
$$

This is obviously not a unique procedure and is a matter of subjective choice of dimensionless parameters. Multiple regression analysis was applied to find out the relationships between dimensionless parameters (Sinnakaudan et al., 2006). Nonlinear least-squares data fitting by Gauss-Newton method was applied.

\section{DISCUSSION OF RESULTS \\ Relation between supplied sediment mass and total sediment yield}

Data analysis has revealed a specific pattern of relationships between the amount of supplied sediment and total sediment yield. Figure 4 shows that more sediment was supplied than transported in the tests with intact initial bed, and larger or equal amount of sediment was transported than supplied in the tests with water-worked bed. In the tests with intact initial bed ('-'), more sediment was supplied compared with corresponding tests for water-worked bed ('+'). This pattern was due to the fact that a criterion for the supply rate was to prevent the bed from excessive erosion or deposition. In the tests with water-worked bed, the bed was not as prone to erosion as in '-' tests, at least in the initial flow phase, and consequently less sediment was required to supply.

Grain size distribution of bed surface material was measured after each experimental test but no significant variation was observed (Mrokowska et al., 2016).

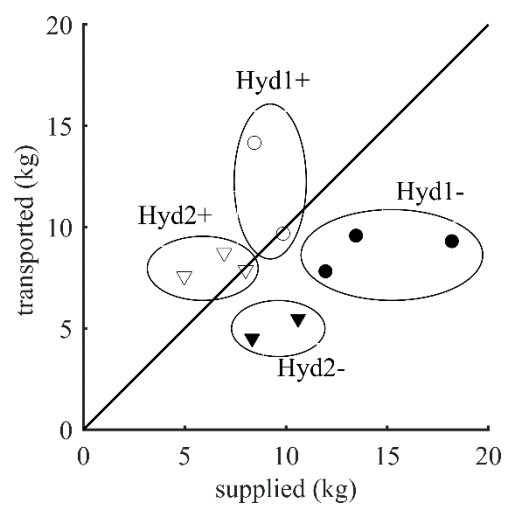

Fig. 4. Supplied and transported mass of the sediment for the experimental tests with intact (' - ') and water-worked ('+') bed. 

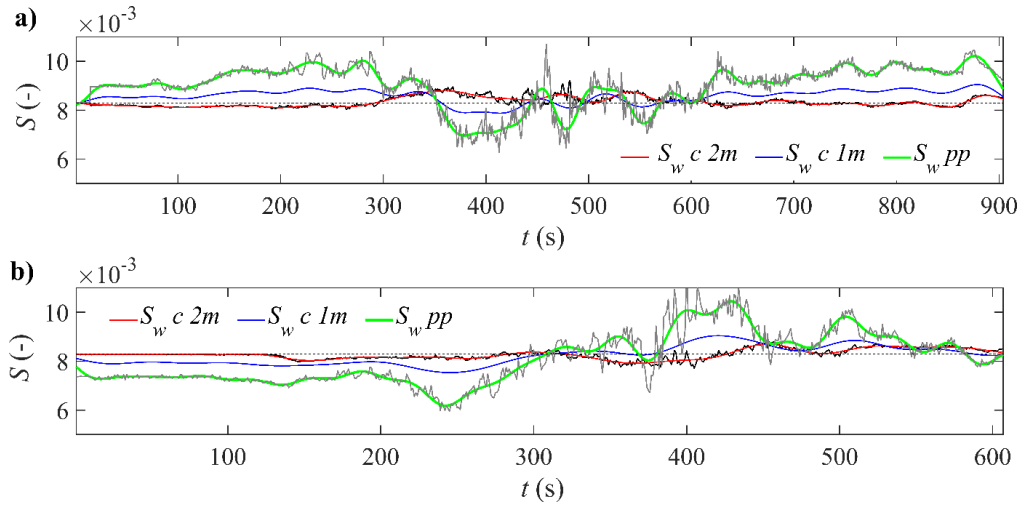

Fig. 5. Temporal variation of water surface slope; a) Hyd1-1, b) Hyd2-1.
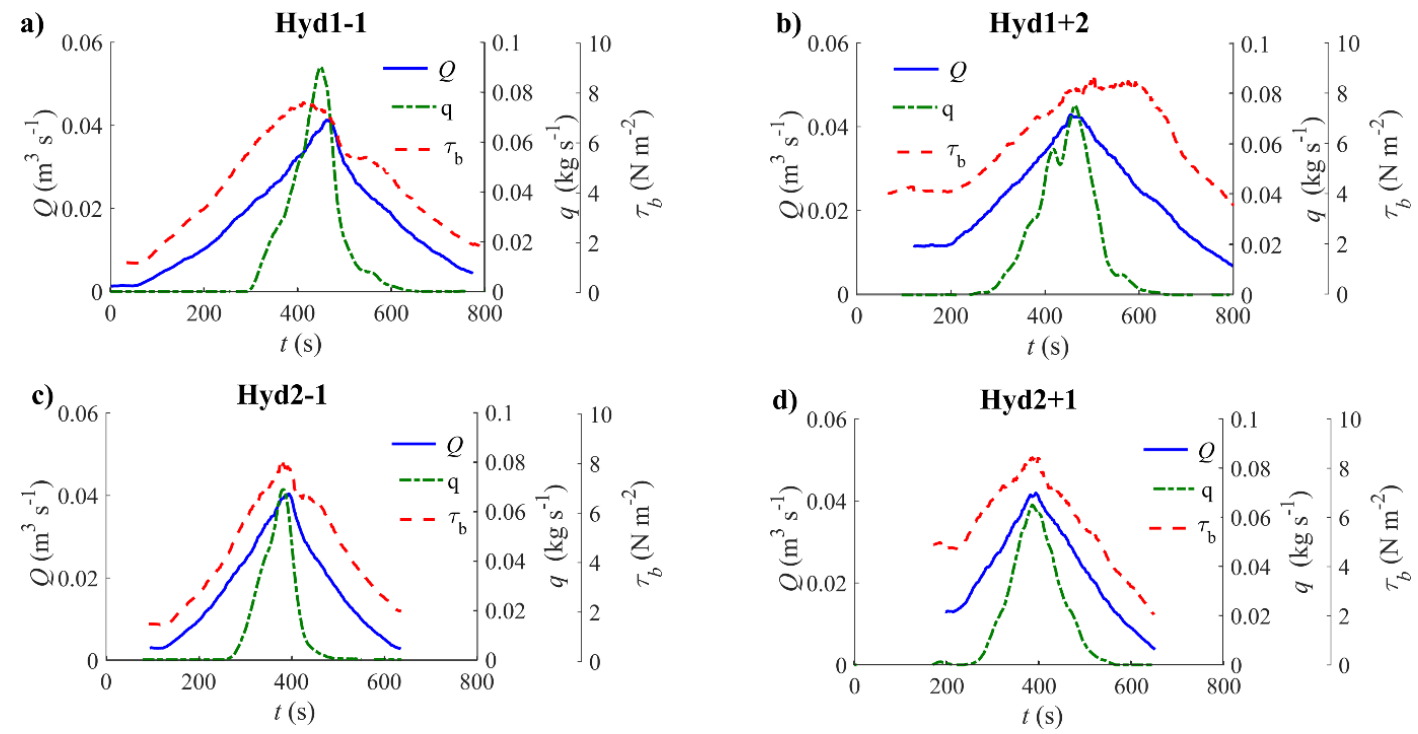

Fig. 6. Temporal variation of flowrate $(Q)$ bedload transport rate $(q)$ bed shear stress $\left(\tau_{b}\right)$ during experimental tests.

\section{Evaluation of water surface slope}

Figure 5 presents a comparison of water surface slope $\left(S_{w}\right)$ results obtained by five point difference quotient, $S_{w} p p$, Eq. (3) for $\Delta x=1 \mathrm{~m}$ and central difference quotient, Eq. (2) for $\Delta x=$ $2 \mathrm{~m}$ and $\Delta x=1 \mathrm{~m}$ denoted by $S_{w} c 2 m$ and $S_{w} c 1 m$, respectively. Black and grey lines represent the results before and colour lines after filtering with Fourier Transform. $S_{w} c 2 m$ proved to be the most reliable evaluation, since its values were closest to bed slope $I=0.0083$ highlighted in Fig. 5 by a dotted line. The results of water surface slope close to bed slope were expected because spatial variability of water depth along the channel was small (less than $1 \mathrm{~cm}$ ).

The figure clearly shows that for five point difference quotient the results were much more noisy than for central difference quotient. This was due to minor spatial water depth fluctuations. They are more likely under mobile bed conditions where erosion and deposition occur than under fixed bed conditions. Moreover, shallow water as in this study (ranging from $2 \mathrm{~cm}$ to $11 \mathrm{~cm}$, see Table 2) also induced these fluctuations. To prevent the formation of eroded and deposited regions inducing fluctuations of water surface slope, sediment was supplied manually to control the supply rate.

A number of similar problems were also pointed out in other studies. Qu (2002) stressed that it was difficult to control water surface slope in laboratory channels. We found that water surface slope was better controlled in the tests with higher rate of unsteadiness, i.e., Hyd2.

\section{Relation between bedload rate and flowrate}

Figure 6 shows a temporal variation of bedload rate $(q)$, flowrate $(Q)$, and bed shear stress $\left(\tau_{b}\right)$ for selected experimental tests. A time lag between the peak flowrate and the peak bedload rate is visible, i.e., in general, the bedload rate attained its peak slightly before the maximum flowrate. The time lag varied between 5 and 13 seconds, except for Hyd1+2 where the maximum bedload rate was observed after the peak flowrate. These results were consistent with the findings of the studies on bedload transport in unsteady flow with unarmoured bed (Humphries et al., 2012; Mao, 2012). Bombar et al. (2011) showed that the time lag directly correlated with the unsteadiness of the hydrograph evaluated from Eq. (1). In this study, no significant differences in time lags between the experimental tests were observed. In fact, both hydrographs had the same value of $P_{g t}$ (Table 2).

The relationship between $Q$ and $q$ under unsteady flow had a form of a clock-wise hysteresis (Fig. 7) indicating that the bedload rate was larger for specific flowrate along the rising limb than along the falling limb of a wave. There is no particular pattern in hysteresis shape that may indicate any impact of flow unsteadiness (difference between Hyd1 and Hyd2 tests) or initial bed condition (difference between '-' and '+' tests) on the bedload transport. This is due to the fact that the sediment was supplied during the experimental tests at a variable rate. Higher bedload rate along the rising limb may be triggered by unlimited sediment supply, mobile bed and higher values of bed 

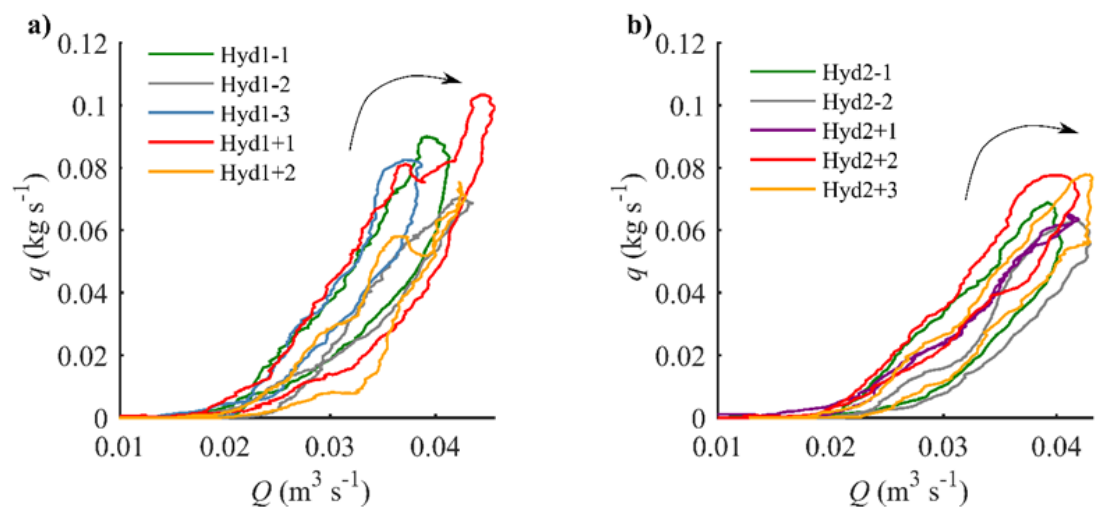

Fig. 7. Relationship between bedload rate $(q)$ and flowrate $(Q)$ for the experimental tests.
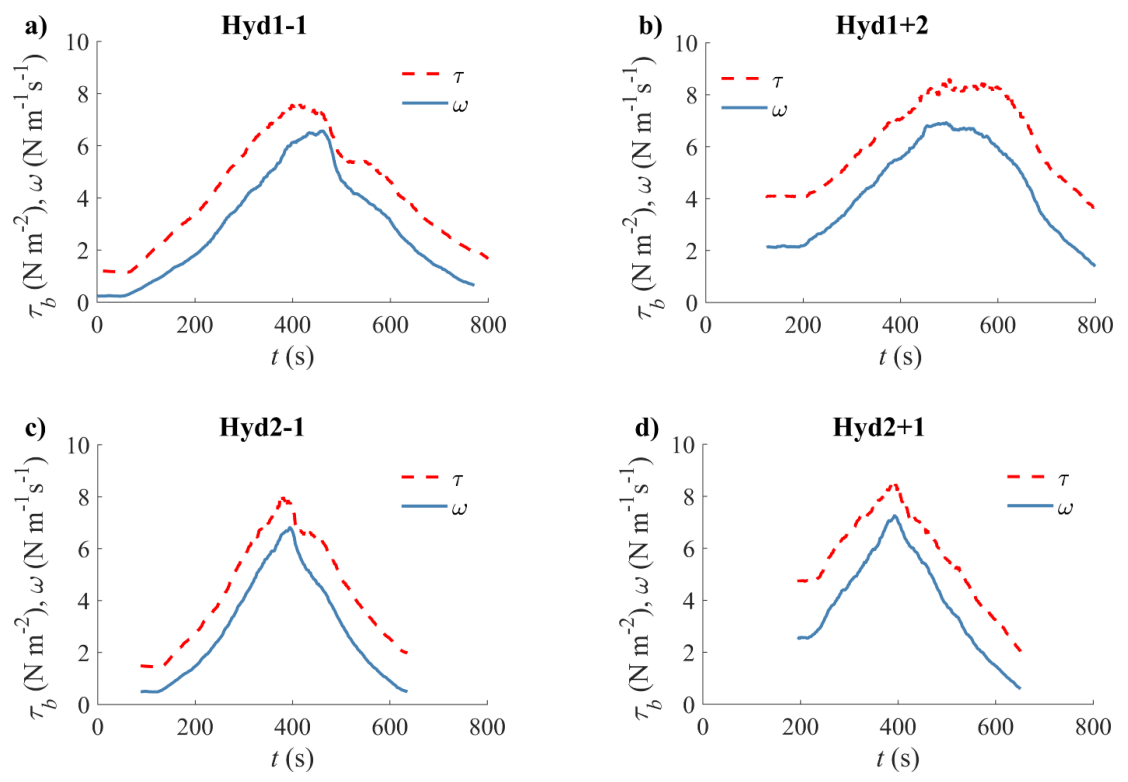

Fig. 8. Temporal variation of bed shear stress $\left(\tau_{b}\right)$ and stream power $(\omega)$ during experimental tests.

shear stress and stream power along the rising limb. The last scenario is discussed in the proceeding section.

\section{Relation between bedload rate, bed shear stress, and stream power}

In general, it is expected that the peak of bed shear stress triggers the peak of the bedload transport in unarmoured beds (Song and Graf, 1996). However, when bed shear stress results are subject to high uncertainty, unexpected variation of this variable may occur. This was the case of Hyd1+2 (Fig. 6b) where the peak bed shear stress occurred along the rising limb as expected but, additionally, unexpectedly high values were observed along the falling limb of the wave. This could be explained by the variation of water surface slope which is significant variable in the bed shear stress formula.

As discussed in the previous sections, input variables for Eq. (4) - water depth $(h)$ and water surface slope $\left(S_{w}\right)$ were problematic to control and evaluate, which was a source of uncertainty in bed shear stress assessment. Mean water depth is usually evaluated based on temporal variation of water level and mean bed level measured after the experimental test. When water depth is shallow, as in our experiment (Table 2), uncertainty of water depth evaluation based on water level and bed topography increases.
Alternatively, the effect of stream power on bedload rate was analysed. The shape of temporal variation of the stream power corresponded to the variation of bed shear stress (Fig. 8) but the impact of water surface slope on the result was suppressed due to multiplication by mean velocity. These results show that stream power may be a good alternative for bed shear stress in the analyses of factors affecting bedload rate, especially when bed shear stress is evaluated from bulk variables and water slope data are of high uncertainty.

The results for stream power were more homogenous than the results for bed shear stress in terms of time lags between peak values. Figure 9 shows a comparison between time lags, $\Delta t$, between the peaks of bedload rate and stream power, and bedload rate and bed shear stress. Peak bedload transport occurred from $\Delta t=-29 \mathrm{~s}$ to $\Delta t=-5 \mathrm{~s}$ after the peak stream power. The variability of lag between the bedload rate and bed shear stress was larger and ranged from $\Delta t=-132 \mathrm{~s}$ and $\Delta t=39 \mathrm{~s}$. The fact that peak bedload rate occurred before the peak of stream power might be attributed to the uncertainty of stream power results.

Despite identified sources of uncertainty, the results show general patterns - both bed shear stress and the stream power were greater along the rising limb resulting in a clock-wise hysteresis (Fig. 10). This is, along with the sediment supply, the explanation for higher bedload rate along rising limbs discussed in the previous section. 


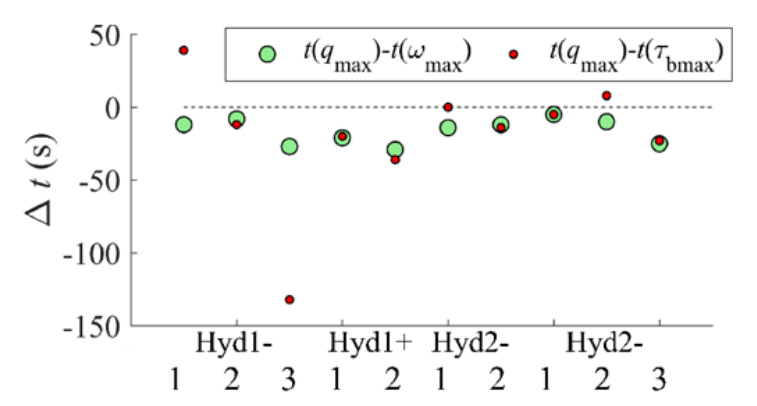

Fig. 9. Time lags, $\Delta t$, between the peaks of bedload rate $\left(q_{\max }\right)$ and stream power $\left(\omega_{\max }\right)$ and the peaks of bedload rate and bed shear stress $\left(\tau_{b \max }\right)$.

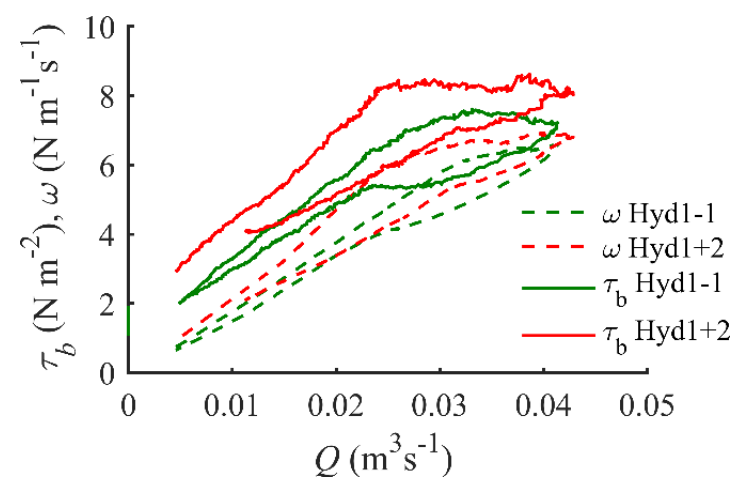

Fig. 10. Relationship between bed shear stress $\left(\tau_{b}\right)$ and flowrate $(Q)$ and stream power $(\omega)$ and flowrate $(Q)$ for sample experimental tests.

- Hyd1- • Hyd1+ • Hyd2- • Hyd2+
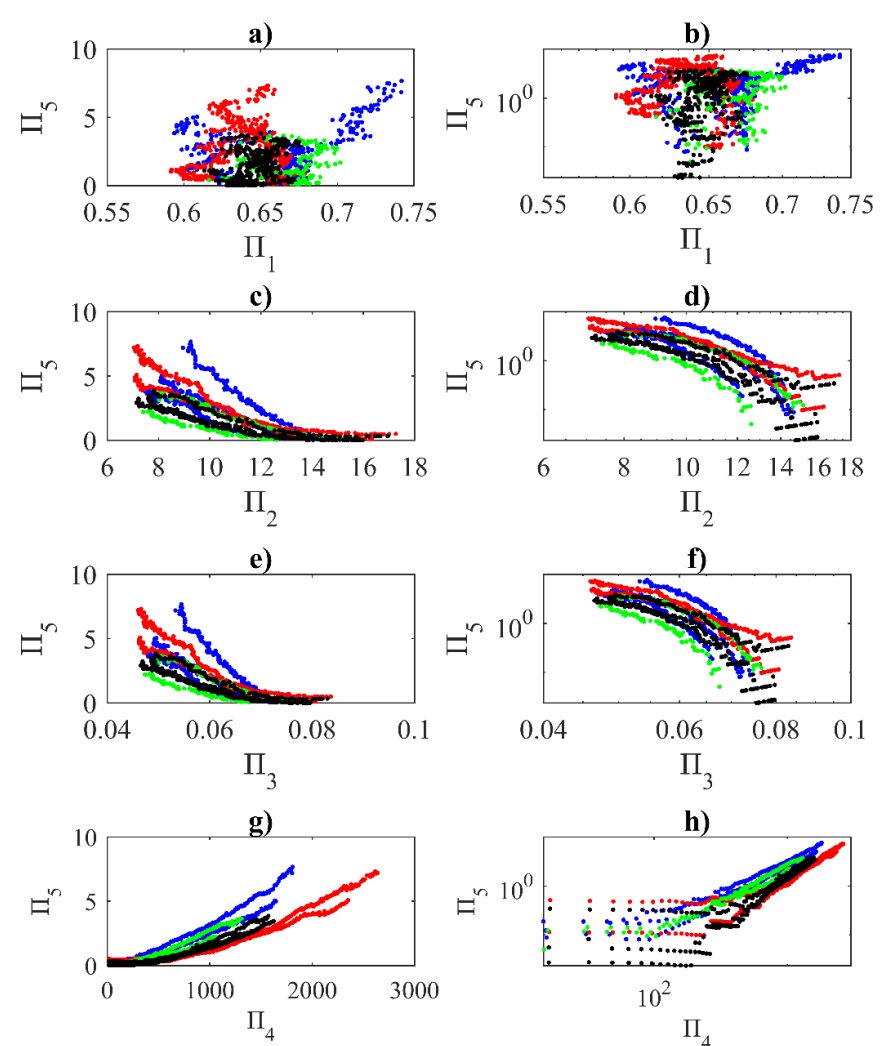

Fig. 11. Relations between independent and dependent dimensionless parameters.

\section{Multiple regression analysis}

Parameter $\pi_{5}=M^{-1} h^{3} \rho$ expressing dimensional cumulative mass was chosen as a dependent parameter. A correlation between the dependent parameter $\pi_{5}$, and independent parameters, $\pi_{1}, \pi_{2}, \pi_{3}, \pi_{4}$ was tested for the rising limbs of the hydrographs.

Figure 11 shows the relation between dimensionless parameters on normal and log-log scales. The graphs reveals a linear relation between $\pi_{5}$ and $\pi_{2}, \pi_{3}$, and a power relation between $\pi_{5}$ and $\pi_{4}$. There was no correlation between $\pi_{5}$ and $\pi_{1}$, and consequently $\pi_{1}$ was not taken into account in the model development. Three independent dimensionless variables, $\pi_{2}, \pi_{3}, \pi_{4}$, were selected to find relevant expressions for the dependent variable $\pi_{5}$ :

$M^{-1} h^{3} \rho=f\left(h^{-1} d, \Delta g^{-0.5} h^{-1.5} v, \Delta g^{0.5} t h^{-0.5}\right)$

A general form of the model indicates that bedload transport does not directly depend on mean velocity, $U$. Performance of various models was tested and assessed based on the coefficient of determination and Nash-Sutcliff coefficient. The best fit model was as follows:

$\pi_{5}=b_{1}+b_{2} \pi_{2}+b_{3} \pi_{3}+b_{4} \pi_{4}^{b_{5}}$

This model fitted independently four groups of data: Hyd1-, Hyd1+, Hyd2-, Hyd2+ for which the regression parameters $b_{1}, \ldots, b_{5}$ were identified. The resulting models for Hyd1-, Hyd1+, Hyd2-, Hyd2+ are presented below:

$$
\begin{aligned}
& M^{-1} h^{3} \rho=-16.684-1.832\left(\frac{v}{\Delta g^{0.5} h^{1.5}}\right)+594.222\left(\frac{d}{h}\right)+ \\
& +192 * 10^{-6} *\left(\frac{\Delta g^{0.5} t}{h^{-0.5}}\right)^{1.426} \\
& M^{-1} h^{3} \rho=-24.828-2.424\left(\frac{v}{\Delta g^{0.5} h^{1.5}}\right)+803.105\left(\frac{d}{h}\right)+ \\
& +24 * 10^{-6} *\left(\frac{\Delta g^{0.5} t}{h^{-0.5}}\right)^{1.672} \\
& M^{-1} h^{3} \rho=-15.045-2.380\left(\frac{v}{\Delta g^{0.5} h^{1.5}}\right)+667.100\left(\frac{d}{h}\right)+ \\
& +21 * 10^{-6} *\left(\frac{\Delta g^{0.5} t}{h^{-0.5}}\right)^{1.709} \\
& M^{-1} h^{3} \rho=-12.967-1.187\left(\frac{v}{\Delta g^{0.5} h^{1.5}}\right)+401.719\left(\frac{d}{h}\right)+ \\
& +44^{*} 10^{-6} *\left(\frac{\Delta g^{0.5} t}{h^{-0.5}}\right)^{1.609}
\end{aligned}
$$

Figure 12 presents a comparison between cumulative mass data and the results from the models. Results for cumulative mass obtained from the models fitted the data very accurately both coefficients, the coefficient of determination and NashSutcliff coefficient, were about 0.99 . 

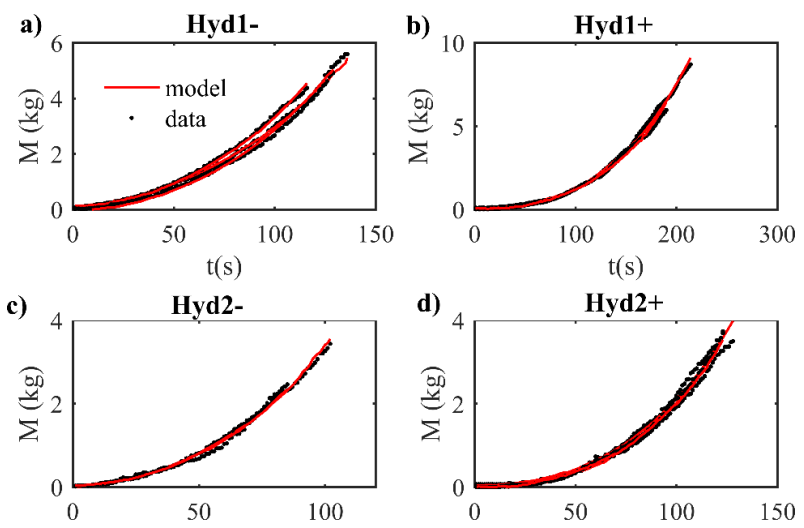

$\mathrm{t}(\mathrm{s})$

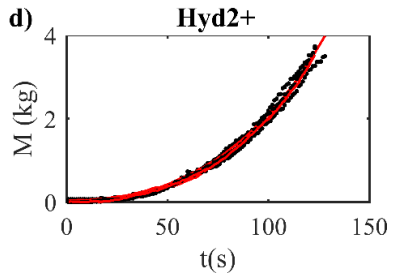

Fig. 12. Comparison of data and regression models for cumulative mass transport.

The above regression models were valid only for the experimental conditions presented in this study. Applicability to other conditions needs to be verified. The models may be used during further experimental tests in similar conditions.

\section{CONCLUDING REMARKS}

In this study, we demonstrated the impact of initial bed conditions and flow unsteadiness on total sediment yield and bedload transport rate. The effect of initial bed conditions was particularly visible in the analysis of total supplied and transported sediment mass. Different proportions between the amount of supplied and transported sediment for the sets of initial conditions revealed a significant role of bed material sorting and bed roughness in the sediment transport during a flood wave propagation.

The study showed that unsteadiness of flow triggered variable bed shear stress and stream power that consequently affected bedload transport rate. It was indicated by the fact that the bedload rate, bed shear stress and stream power were in clockwise hysteretic relationship with the flowrate.

A number of questions have arisen regarding data interpretation and definitions. Bed shear stress definition and measurement methods induce high uncertainty and difficulty in data interpretation. As each method of evaluation of the bed shear stress is uncertain to some extent, a comparison of a few methods may be helpful in interpreting the results as shown in other studies (Bombar, 2016; Qu, 2002).

The study showed that when bed shear stress is evaluated from bulk variables the results may be highly affected by the uncertainty of input variables, especially water surface slope. In such cases, stream power turns out to be less sensitive to the uncertainty of water surface slope and therefore may be more adequate than the bed shear stress in the analyses of factors affecting bedload rate. In other words computations of stream power led to more homogenous results.

The study revealed some problems regarding the experimental design and performance. The most serious one was to avoid water surface slope fluctuations in a flume for the mobile bed and shallow flow. We noticed smaller fluctuations for the tests with higher rate of unsteadiness. For such cases, evaluation of the variables based on water depth and water surface slope such as bed shear stress and stream power is more reliable.

It is crucial to control the impact of physical variables on the experimental results. Classical physical methods, such as dimensional analysis may help to understand relations between the bedload transport and the parameters governing its dynamics. In this study, a set of five dimensionless parameters and multiple regression model for dimensional cumulative mass were identified. The best fit model was as follows: $\pi_{5}=b_{1}+b_{2} \pi_{2}+b_{3} \pi_{3}+b_{4} \pi_{4}^{b_{5}}$.

The regression parameters $b_{1}, \ldots, b_{5}$ were identified for experimental data. These results may be used in future design of similar experiments.

Acknowledgements. This study has been partially financed by National Science Centre. Grant No. DEC2011/01/N/ST10/07395 and partially within statutory activities No. 3841/E-41/S/2016 and 202961/E-377/S/2016 assigned by the Ministry of Science and Higher Education of Poland.

\section{REFERENCES}

Ahanger, M.A., Asawa, G.L., Lone, M.A., 2008. Experimental study of sediment transport hysteresis. Journal of Hydraulic Research, 46, 5, 628-635. DOI:10.3826/jhr.2008.3185.

Bagherimiyab, F., Lemmin, U., 2013. Shear velocity estimates in rough-bed open-channel flow. Earth Surface Processes and Landforms, 38, 14, 1714-1724. DOI: 10.1002/esp.3421.

Bendat, J., Piersol, A.G., 2010. Random Data: Analysis and Measurement Procedures. Wiley, Hoboken, NJ.

Bizzi, S., Lerner, D.N., 2015. The use of stream power as an indicator of channel sensitivity to erosion and deposition processes. River Research and Applications, 31, 1, 16-27. DOI: 10.1002/rra.2717.

Bombar, G., 2016. Hysteresis and Shear Velocity in Unsteady Flows. Journal of Applied Fluid Mechanics, 9, 2, 839-853.

Bombar, G., Elci, S., Tayfur, G., Guney, S., Bor, A., 2011. Experimental and numerical investigation of bed-load transport under unsteady flows. Journal of Hydraulic Engineering-ASCE, $137, \quad 10, \quad 1276-1282 . \quad$ DOI: $10.1061 /$ (asce)hy.19437900.0000412.

Cao, D.P., Chiew, Y.M., Yang, S.Q., 2016. Injection effects on sediment transport in closed-conduit flows. Acta Geophysica, 64, 1, 125-148. DOI: 10.1515/acgeo-2015-0064.

Cooper, J.R., Tait, S.J., 2009. Water-worked gravel beds in laboratory flumes - a natural analogue? Earth Surface Processes and Landforms, 34, 3, 384-397. DOI: 10.1002/esp.1743.

De Sutter, R., Verhoeven, R., Krein, A., 2001. Simulation of sediment transport during flood events: laboratory work and field experiments. Hydrological Sciences Journal-Journal Des Sciences Hydrologiques, 46, 4, 599-610. DOI: 10.1080/02626660109492853.

Dey, S., 2014. Fluvial Hydrodynamics: Hydrodynamic and Sediment Transport Phenomena, Fluvial Hydrodynamics: Hydrodynamic and Sediment Transport Phenomena. GeoPlanetEarth and Planetary Sciences. Springer, 687 p. DOI: 10.1007/978-3-642-19062-9.

Dottori, F., Martina, M.L.V., Todini, E., 2009. A dynamic rating curve approach to indirect discharge measurement. Hydrology and Earth System Sciences, 13, 6, 847-863.

Ettema, R., 2000. Hydraulic modelling: concepts and practice, ASCE manuals and reports on engineering practice no. 97. American Society of Civil Engineers, Reston, VA, USA.

Ferreira, R.M.L., Franca, M.J., Leal, J.G.A.B., Cardoso, A.H., 2012. Flow over rough mobile beds: Friction factor and vertical distribution of the longitudinal mean velocity. Water Resources Research, 48. DOI: 10.1029/2011wr011126.

Galia, T., Hradecky, J., 2011. Bedload transport and morphological effects of high-magnitude floods in small headwater streams Moravskoslezske Beskydy Mts. (Czech Republic). Journal of Hydrology and Hydromechanics, 59, 4, 238-250. DOI: 10.2478/v10098-011-0020-x. 
Gharbi, M., Soualmia, A., Dartus, D., Masbernat, L., 2016. Floods effects on rivers morphological changes application to the Medjerda River in Tunisia. Journal of Hydrology and Hydromechanics, 64, 1, 56-66. DOI: 10.1515/johh-2016-0004.

Guney, M.S., Bombar, G., Aksoy, A.O., 2013. Experimental study of the coarse surface development effect on the bimodal bedload transport under unsteady flow conditions. Journal of Hydraulic Engineering-ASCE, 139, 1, 12-21. DOI: 10.1061/(asce)hy.1943-7900.0000640.

Guo, J., 2015. Sidewall and non-uniformity corrections for flume experiments. Journal of Hydraulic Research, 53, 2, 218-229. DOI: $10.1080 / 00221686.2014 .971449$.

Haddadchi, A., Omid, M.H., Dehghani, A.A., 2013. Bedload equation analysis using bed load-material grain size. Journal of Hydrology and Hydromechanics, 61, 3, 241-249. DOI: 10.2478/johh-2013-0031.

Humphries, R., Venditti, J.G., Sklar, L.S., Wooster, J.K., 2012. Experimental evidence for the effect of hydrographs on sediment pulse dynamics in gravel-bedded rivers. Water Resources Research, 48. DOI: 10.1029/2011wr010419.

Julien, P.Y., Klaassen, G.J., Ten Brinke, W.B.M., Wilbers, A.W.E., 2002. Case study: Bed resistance of Rhine River during 1998 flood. Journal of Hydraulic Engineering-ASCE, 128, 12, 1042-1050. DOI: $\quad 10.1061 /$ (asce) $0733-$ 9429(2002)128:12(1042).

Kuhnle, R.A., 1992. Bed-load transport during rising and falling stages on 2 small streams. Earth Surface Processes and Landforms, 17, 2, 191-197. DOI: 10.1002/esp.3290170206.

Lee, K.T., Liu, Y.L., Cheng, K.H., 2004. Experimental investigation of bedload transport processes under unsteady flow conditions. Hydrological Processes, 18, 13, 2439-2454. DOI: $10.1002 /$ hyp. 1473 .

Mao, L., 2012. The effect of hydrographs on bed load transport and bed sediment spatial arrangement. Journal of Geophysical Research-Earth Surface, 117. DOI: 10.1029/2012jf002428.

Mao, L., Cooper, J.R., Frostick, L.E., 2011. Grain size and topographical differences between static and mobile armour layers. Earth Surface Processes and Landforms, 36, 10, 13211334. DOI: $10.1002 /$ esp. 2156.

Michalik, A., Książek L., 2009. Dynamics of water flow on degraded sectors of Polish mountain stream channels. Polish Journal of Environmental Studies, 18, 4, 665-672.

Moog, D.B., Whiting, P.J., 1998. Annual hysteresis in bed load rating curves. Water Resources Research, 34, 9, 2393-2399. DOI: 10.1029/98wr01658.

Mrokowska, M.M., Rowiński, P.M., Kalinowska, M.B., 2015a. A methodological approach of estimating resistance to flow under unsteady flow conditions. Hydrology and Earth System Sciences, 19, 10, 4041-4053. DOI: 10.5194/hess-19-4041-2015.

Mrokowska, M.M., Rowiński, P.M., Kalinowska, M.B., 2015 b. Evaluation of friction velocity in unsteady flow experiments. Journal of Hydraulic Research, 53, 5, 659-669. DOI: 10.1080/00221686.2015.1072853.

Mrokowska, M., Rowiński, P., Książek, L., Strużyński, A., Wyrębek, M., Radecki-Pawlik, A., 2016. Flume experiments on gravel bed load transport in unsteady flow - preliminary results. In: Rowiński, P., Marion, A. (Ed.): Hydrodynamic and Mass Transport at Freshwater Aquatic Interfaces. Geoplanet: Earth and Planetary Sciences. Springer International Publishing Switzerland, Berlin, Heidelberg, pp. 221-233. DOI: 10.1007/978319-27750-9_18.
Nikora, V., McEwan, I., McLean, S., Coleman, S., Pokrajac; D., Walters, R., 2007. Double-averaging concept for rough-bed open-channel and overland flows: Theoretical background. Journal of Hydraulic Engineering-ASCE, 133, 8, 873-883. DOI: 10.1061/(asce)0733-9429(2007)133:8(873).

Ockelford, A.-M., Haynes, H., 2013. The impact of stress history on bed structure. Earth Surface Processes and Landforms, 38, 7, 717-727. DOI: 10.1002/esp.3348.

O'Kane, J.P., 2005. Hysteresis in hydrology. Acta Geophysica Polonica, 53, 4, 373-283.

Perumal, M., Shrestha, K.B., Chaube, U.C., 2004. Reproduction of hysteresis in rating curves. Journal of Hydraulic EngineeringASCE, $130, \quad 9, \quad 870-878$. DOI: 10.1061/(asce)07339429(2004)130:9(870).

Phillips, B.C., Sutherland, A.J., 1990. Temporal lag effect in bedload sediment transport. Journal of Hydraulic Research, 28, 1, $5-23$.

Qu, Z., 2002. Unsteady open-channel flow over a mobile bed. Ecole Polytechnique Federale de Lausanne, Lausanne, Switzerland.

Rajwa-Kuligiewicz, A., Bialik, R.J., Rowiński, P.M., 2015. Dissolved oxygen and water temperature dynamics in lowland rivers over various timescales. Journal of Hydrology and Hydromechanics, 63, 4, 353-363. DOI: 10.1515/johh-20150041.

Rowiński, P.M., Czernuszenko, W., Pretre, J.M., 2000. Timedependent shear velocities in channel routing. Hydrological Sciences Journal-Journal Des Sciences Hydrologiques, 45, 6, 881-895. DOI: 10.1080/02626660009492390.

Rowiński, P.M., Czernuszenko, W., 1998. Experimental study of river turbulence under unsteady conditions. Acta Geophysica Polonica, 46, 4, 461-480.

Savitzky, A., Golay, M., 1964. Smoothing and differentiation of data by simplified least squares procedures. Analytical Chemistry, 36, 1627-1639. DOI: 10.1021/ac60214a047.

Sinnakaudan, S.K., Ab Ghani, A., Ahmad, M.S.S., Zakaria, N.A., 2006. Multiple linear regression model for total bed material load prediction. Journal of Hydraulic Engineering-ASCE, 132, 5, 521-528. DOI: 10.1061/(asce)0733-9429(2006)132:5(521).

Song, T., Graf, W.H., 1996. Velocity and turbulence distribution in unsteady open-channel flows. Journal of Hydraulic Engineering-ASCE, 122, 3, 141-154. DOI: 10.1061/(asce)0733-9429(1996)122:3(141).

Sun, H., Chen, D., Zhang, Y., Chen, L., 2015. Understanding partial bed-load transport: Experiments and stochastic model analysis. Journal of Hydrology, 521, 196-204. DOI: 10.1016/j.jhydrol.2014.11.064.

Tabarestani, M.K., Zarrati, A.R., 2015. Sediment transport during flood event: a review. International Journal of Environmental Science and Technology, 12, 2, 775-788. DOI: 10.1007/s13762-014-0689-6.

Talukdar, S., Kumar, B., Dutta, S., 2012. Predictive capability of bedload equations using flume data. Journal of Hydrology and Hydromechanics, 60, 1, 45-56. DOI: 10.2478/v10098-0120004-5.

Wang, L., Cuthbertson, A.J.S., Pender, G., Cao, Z., 2015. Experimental investigations of graded sediment transport under unsteady flow hydrographs. International Journal of Sediment Research, 30, 4, 306-320. DOI: 10.1016/j.ijsrc.2015.03.010.

Yalin, M.S., 1972. Mechanics of Sediment Transport. Pergamon Press, Oxford, UK, 288 p. 